\title{
Literatura de combate de la mujer americana en el conflicto independentista ${ }^{1}$
}

\author{
Juan Antonio Frago ${ }^{* *}$ \\ Universidad de Zaragoza, España
}

\begin{abstract}
Resumen
Se estudia aquí el Memorial de un grupo de mujeres de la elite criolla, escrito durante el asedio de Montevideo por los porteños de Rondeau y las huestes orientales de Artigas. La pieza literaria tiene la forma de una instancia oficial matizada de lenguaje forense, con petición y alegación de motivos extendidas en doce décimas. Se trataba de una primeriza incursión femenina en la literatura de compromiso en el curso de los avatares que llevaron a las independencias americanas, en este caso objeto de propaganda a favor del bando realista. Este texto presenta los perfiles retóricos de la postura de las mujeres ante el conflicto armado que vivían, y rasgos que lo encuadran en la norma culta del español americano de la época.
\end{abstract}

Palabras clave: la mujer y el independentismo, literatura propagandística, estilo forense y literario, la norma americana.

1 Del proyecto de investigación FFI2011-24806, Ministerio de Economía y Competitividad.

** Para correspondencia, dirigirse a: Juan Antonio Frago Gracia (jafrago@unizar.es), Departamento de Lingüística General e Hispánica, Facultad de Filosofía y Letras, Universidad de Zaragoza, Pedro Cerbuna 12, 50009 Zaragoza, España. 


\title{
COMBAT Literature of AMERICAN WOMEN IN THE INDEPENDENCE CONFLICT
}

\begin{abstract}
This is a study of the Memorial of a group of elite creole women, written during the siege of Montevideo by the followers of Rondeau and Artigas. This literary piece has the form of an official request coloured with forensic language, with petitions and allegations in twelve ten-line stanzas. It was the first female incursion in commitment literature in the course of the events leading to LatinAmerican countries independence, in this case favouring the royalist faction. This text presents the rhetoric profiles of women's stance in the face of the armed conflict situation in which they were living, and the features that frame it within the educated Spanish standard of that time.
\end{abstract}

Key words: woman and independentism, propagandistic literature, forensic and literary style, American standard.

Recibido: 15/07/13 Aceptado: 06/09/13

\section{EL TEXTO $^{2}$}

Memorial de las damas de Montevideo a su Comandan[te] General el señor Bigodet

\author{
Excmo. Señor: \\ El noble y bello sexo \\ de esta Plaza (terror de las naciones), \\ epílogo y complexo \\ de valor, hermosura y perfecciones,
}

2 Composición poética publicada en el periódico gaditano El Procurador General de la Nación y del Rey, núm. 202, 21-IV-1813, pp. 1668-1670, original conservado en la Biblioteca de Temas Gaditanos (Cádiz). El título bajo el que los versos se editan seguramente venía ya en las originales hojas montevideanas impresas o manuscritas. 
hace con atención y reverencia la propuesta siguiente a V. E.

I) Las damas de esta ciudad del patriotismo guiadas y a la guerra acostumbradas desde su más tierna edad, con toda serenidad a Vuecelencia ofrecemos que si es preciso saldremos al Christo o las Tres Cruces a desplumar avestruces de los que al frente tenemos.

II) Fundada en ley y en razón creemos todas que sea nuestra magnánima idea, nuestra justa pretensión. En esta suposición, denos armas Vuecelencia y concédanos licencia para salir brevemente a batir al insurgente o a mostrarle resistencia.

III) Nosotras, aunque inferiores en fuerzas al militar, al mundo sabremos dar lecciones muy superiores. los confites silvadores, la incomodidad, el frio, ni aun el caloroso estío nos darán temor ni miedo. Tal será nuestro denuedo, tal nuestro valor y brio.

IV) Si fueren arduas empresas las que habemos concebido, 
mayores las han vencido

las valientes geronesas, también las aragonesas y las gallegas leales han teñido sus puñales, han dado fuego al cañón, y han sido a Napoleón terribles antemurales.

V) Aquellas nobles hispanas nos han dado un buen exemplo, pues se han presentado al templo de la gloria muy ufanas. Y así las americanas, hijas de aquellas matronas, qual valientes Amazonas deseamos la venganza y enristrar pronto la lanza, y las espadas tizonas.

VI) Habrá algunas opiniones contrarias a nuestro intento, mas todas en un momento se rebaten con razones. Entre sayas y calzones la diferiencia no es mucha; la muger estando en lucha, con el demonio pelea y el más guapo tituvea si se presenta en la lucha.

VII) No dudamos que hay soldados valerosos y aguerridos, mas hay pocos escogidos y son muchos los llamados. No todos los bien peinados, los dengues y los quijotes 
obtienen aquellos dotes

que al buen militar exaltan, pues a infinitos les faltan

las barbas y los bigotes.

VIII) En tal caso bien podemos

(por una ley exclusiva)

entrar en la alternativa

con ellos, y así lo haremos.

Nosotras, Señor, creemos

que es de nuestra obligación

desalojar el cordón

de esa vil e infame raza,

si a individuos de esta Plaza

les falta resolución.

IX) Dénsenos las municiones, armamento y cartucheras, que baxo nuestras polleras se verán muchos calzones. Y mientras los maricones reposan en lecho blando, mientras están pretextando asmas, dolores y potras, defenderemos nosotras los derechos de Fernando,

X) Nosotras tenemos arte para vencer a Cupido, y qué ¿no será rendido Júpiter y el mismo Marte? Sí, Señor, por nuestra parte no se perderá la acción; tenemos disposición para quanto nos ordenen, mientras otros se entretienen pintando al Padre Simón. 
XI) Con que puede Vuecelencia, vista la instancia presente, decretar lo conveniente según lo exige la urgencia. Y verá con complacencia el fenómeno más raro, verá cómo paga caro Rondeau su orgullo y arrojo, y por fin verá el despojo del General Tupacamaro.

XII) Así lo firmamos Juana Venavides y Montoya, Francisca Isabel Bedoya, y Margarita Zambrana, Melchora de la Quintana, Encarnación Avilés, Hipólita Nabacenés, Petrona Díaz Abrantes, y por todas las restantes firmo yo, Maria Inés.

Decreto

Con detención madura examinada la presente instancia, he decretado con esta fecha, y por presentada se tenga, y córrase traslado a los hombres, quienes contestada la debuelvan al punto y, ya informado por su respuesta, oiré a las heroynas si deben o no tratarlos de gallinas.

Proveído

Lo mandó, de que doy fe, por ante mí el Escribano, firmándola de su mano el general Bigodet. 


\section{LA FORMA LITERARIA DEL MEMORIAL}

2.1. De la existencia de este que llama "poema laudatorio independiente" dio cuenta Rodríguez Gutiérrez, para quien "El Memorial está escrito en varios metros: una silva, una quintilla, una décima y pareados. El Decreto final es una octava", y dicha estudiosa opina que esta composición "se encuentra fuera de la temática general de esta etapa", y que con ella se buscaba "poner en evidencia a aquellos refugiados en Cádiz que se apartan de la vida militar cuando deberían prestar sus servicios en la guerra contra Napoleón" $(2006: 334,376)^{3}$. Quedándome por ahora en lo que es la forma literaria del Memorial, debe señalarse que en realidad consta de un sextetolira ( $\mathrm{aBaBCC})$, estrofa empleada por fray Luis de León, variante de la creada por San Juan de la $\mathrm{Cruz}^{4}$, más doce décimas a las que siguen la octava del Decreto y la redondilla del Proveído (abba).

La métrica del sexteto-lira del comienzo es correcta, con el sexto verso endecasílabo, pues las iniciales de la forma de tratamiento $V$. E. corresponden al Vuecelencia que aparece en las décimas I, II y XI; el octavo de esta (Rondeau su orgullo y arrojo) para ser octosílabo exige el silabeo Rondeau ${ }^{5}$, mientras el siguiente es de nueve sílabas con el nombre indígena Tupac Amaro, no así con la por entonces variante Tupacmaro ${ }^{6}$, igual que eneasilabo es el séptimo de la última décima (Hipólita Nabacenés) con el apellido que presenta ${ }^{7}$, pero la versificación de las doce décimas en cuanto a la forma es prácticamente la apropiada, y del todo adecuada la requerida por la redondilla final. Mayores problemas ocasionó a la autora, o las coautoras, la adecuación del formulario lenguaje forense a la octava real del Decreto

\footnotetext{
3 Esto es todo lo que dicha autora dice de este Memorial, simplemente incluido también entre los "poemas laudatorios" del índice cronológico de su artículo (376).

4 Define esta estrofa Quilis, pero con el verso 5 heptasílabo (1975: 101-102).

5 Por realización a la francesa de este patrónimo o por antihiato en la secuencia e-áu (> éau); de todos modos, parece haber habido en Argentina continuidad en la pronunciación Rondó, que desde la escuela se enseña. En cuanto a la rima de los versos 1 y 4 de la redondilla ( $f e$-Bigodet), es consonante si el nombre propio se pronuncia sin su $-t$, por su pérdida directa o por la de una /-d/ con que la dental sorda fácilmente podría trocarse.

6 Tupacmaru y Tupacmaro fueron variantes de uso frecuente, la primera corría en Cochabamba durante la insurrección del caudillo indígena así llamado, como en otra parte documento (2010: 246), y Tupacmaro se encuentra en sermón de un cura del Arzobispado de Lima, de la misma época: Biblioteca Nacional de España (BNE), Mss. 20245-23.

Solo un buen conocimiento de la onomástica personal montevideana de la época, del que carezco, me permitiría suponer que este Nabacenés en el original fuera en realidad Navascués, apellido muy conocido en las provincias vascongadas, Navarra y Aragón.
} 
(ABABABCC), cuyos versos 4 y 5 son de diez sílabas, y el 7 endecasílabo si en oiré hay sinéresis antihiática (oi-ré).

2.2. Pero el Memorial de las damas de Montevideo no es un "poema laudatorio", como la citada autora suponía, pues no está escrito en alabanza de Vigodet, sino en apoyo de los realistas que a la sazón dominaban la asediada plaza montevideana y para enardecer los ánimos de hombres renuentes a participar en la lucha. El Memorial con tal fin está compuesto por iniciativa de las distinguidas mujeres de la buena sociedad cisplatina que "firman" en la última décima, seguramente con la participación en su autoría de algunas de ellas, tal vez asesoradas por alguien experto en la parte forense del corpus. Por lo que al aspecto puramente literario concierne, en el ambiente cultural americano de la época la décima ningún secreto debía de guardar para señoras de la elite criolla, cuando su manejo era corriente incluso en medios populares ${ }^{8}$.

Es un hecho sobradamente conocido que en la sociedad indiana arraigó profundamente esta combinación métrica, empleada incluso como medio de propaganda política de fondo indigenista ${ }^{9}$ y su presencia es numerosísima en todo tipo de papeles, manuscritos e impresos, de los años próximos a la Independencia ${ }^{10}$. Se puede hallar la décima hecha en sátira contra las Cortes gaditanas y la promulgación de la Constitución, "para llenar este hueco", en carta escrita el 19 de mayo de 1811 por el bogotano José Gregorio Gutiérrez Moreno (Vanegas Useche 2011: 212); así también la burlesca dada y sellada por la Contaduría General del Uruguay el 8 de noviembre de 1832, en respuesta a una solicitud del negro Ventura de Molina (2010: 236), o la de trágico aliento grafiada en la pared de la Acordada por un preso en vísperas de su ahorcamiento, en el agosto de 1817 (Frago Gracia 2012a: 74).

\footnotetext{
8 De autoría popular sin duda son no pocas décimas de las recogidas en la colección de Flores Alatorre abajo citada (v. n. 10).

9 Así en las décimas Aviso al público que se fijaron en la plaza del Cuzco tras el levantamiento de Tupac Amaro, en 1781, favorables a la rebelión indígena: BNE, Mss. 10955, fs. $127 \mathrm{v}-128 \mathrm{v}$.

10 Los fondos de la BNE abundan en testimonios de composiciones en décimas, por ejemplo las de la invectiva contra Hidalgo (Mss. 20348), o el Libro de décimas de José María Flores Alatorre (Mss. 13862), entre otras muchas muestras textuales del género.
} 


\section{ENTRE CÁDIZ Y MONTEVIDEO}

3.1. En fondos archivísticos gaditanos se encuentran documentos relativos a la Banda Oriental, así el poder que a Francisco Javier Elío otorgó "la Muy Fiel y Reconquistadora Ciudad de San Felipe y Santiago de Montevideo, a tres de abril de 1810", para que "se estime que esta ciudad, tan importantísima por su situación y por su numerosa población, pueda tener derecho a un diputado para las Cortes", atendiendo al "mucho conocimiento que ha adquirido en el tiempo que existe en esta Vanda", y por el "conocimiento que tan de cerca ha tomado del estado de estos payses y de lo que les falta y necesitan para su mayor seguridad" ${ }^{11}$. Era, en efecto, apreciada por los criollos la familiarización del español con la realidad americana y denostada su ignorancia, sobre todo la de quienes tenían responsabilidades en asuntos de gobierno. Precisamente en la enérgica intervención del diputado por Perú, Dionisio Inca Yupanqui, en la sesión del 16 de diciembre de 1810, el cuzqueño advertía que respecto de "sus obligaciones con las Américas, V. M. no las conoce", y que "la mayor parte de sus diputados y de la Nación apenas tienen noticia de este dilatado continente" (Quintero González 2011:295).

En la prensa gaditana, un hervidero de publicaciones de desigual fortuna durante cuatro años, las cuestiones americanas, que para los españoles debían ser de capital importancia, tal y como los acontecimientos sociales y militares se estaban desarrollando por entonces al otro lado del Atlántico, no ocuparon las páginas impresas que eran de esperar. De principal orientación americanista sería El Político Imparcial, editado en la Isla de León y del que escasas noticias se tienen; también el Telégrafo Mexicano, cuya vida se extendió desde el 28 de febrero al 21 de agosto de 1813, y el Telégrafo Americano, del que entre 1811 y 1812 aparecerían veinte números (Sánchez Hita 2006: 67-68, 107). El editor de este periódico ya en su primer número sospechaba que lo americano no iba a despertar una entusiasta acogida en el público lector, y, efectivamente, su regularidad semanal conoció dos incumplimientos; en el segundo lamentaba las dificultades económicas de su empresa, "pues como son muy pocos los que se quieren instruir de lo que se refiere a América, hay corta venta", y en el número veinte, y último de esta publicación periódica, concluía: "Siento mucho que la España sigue 
embrollada como hasta aquí sobre sucesos de América, pero no lo puedo remediar" (Sánchez Hita 2006: 68-69).

3.2. Sin embargo, Cádiz mantenía viva su tradición de puerto y puerta de América, título que antes ostentó Sevilla, y en los años de la ocupación napoleónica con mayor razón tendría esa condición de enlace entre la Península y Ultramar ${ }^{12}$. En las discusiones de las Cortes no solo se oyó la voz del diputado Inca Yupanqui, sino también las de otros representantes americanos, entre ellos el que mandó imprimir en esta ciudad la Memoria histórica de la provincia de Chiapa, una de las de Guatemala, presentada al augusto Congreso por el Br. D. Mariano Robles Domínguez ${ }^{13}$. La toponimia urbana decimonónica mostraba la impronta marinera e indiana en términos como La Goleta, Baluarte de los Negros y Cuesta de los Negros (Castro y Rossi 1857/2007: 34, 44), aún pervive hoy en el nomenclátor gaditano un Callejón de los Negritos frente al puerto y al lado de la antigua fábrica de tabacos, y la acendrada relación de Cádiz con los dominios americanos se manifiesta en el vocabulario recogido por este autor ${ }^{14}$. En la misma prensa es posible hallar retazos de gran familiaridad, incluso lingüística, con América, así en este artículo comunicado aparecido en El Procurador General de la Nación y del Rey:

Dicen los americanos en América, con mucha suavidad y lisura: "Llámale mulato, que aunque se cure la herida, le quedará la cicatriz".

12 De hecho, en Cádiz el 31 de enero de 1815 se estipula la nota de los buques que componían el convoy expedicionario a Montevideo bajo el orden en que iban a salir sus divisiones: BNE, Mss. 12976-55; en carta fechada el mes de marzo de 1815, recibida de la Península por el bogotano Agustín Gutiérrez Moreno, se sospechaba que en realidad se trataba del ejército destinado a reconquistar el Virreinato de Nueva Granada (Vanegas Useche 2011: 452). En cualquier parte de América por entonces eran corrientes las menciones a Cádiz, y este mismo independentista colombiano escribía a su hermano José Gregorio del 10 de julio de 1813: "Hoy mismo he recibido carta de Jamaica en que me dicen que en la Gazeta se da la noticia de que por un barco venido de Cádiz a La Habana sabe aquel gobernador que se alistaban 2000 hombres para venir a conquistar a los insurgentes de Cartagena" (413).

13 Real Academia de la Historia, 3/767 (13): Cádiz, Imprenta Tormentaria, 1813, libro de 72 páginas que firmó su autor el 25 de mayo de este año (Cruz González 2006: 159).

${ }_{14} \mathrm{Su}$ Diccionario de voces gaditanas, formado por "palabras, frases y modismos de Cádiz, parte... de origen local y parte adoptados de otras provincias" (pp. I-XVIII), contiene vocablos en coincidencia americana o americanismos léxicos como avellana americana, boruca, cacimba, fletera, guasa, jalón, pelado, potala, socucho, e indigenismos como bojío, guayaba, guasca, pita. 
¿Qué tal, Sr. Procurador? ¿No le parece a su merced, mi amo, que acá se van pegando las costumbres de por allá? Y los papelistas de Cádiz, particularmente mis amos el Redactor y el Conciso, el Diario y la Abejita ¿no parece que han mamado leche de negra?

Y dígame su merced: ¿los apasionados de estos caballeros y sus admiradores, que son más esclavos que los que se venden allá en los barracones, porque veo que los vendicen quando los desuellan, no eran dignos del honor de haber nacido en Guinea, por las altas ideas que tienen de libertad, igualdad y justicia? Yo estoy muy contento, mi amo, con ver mis iguales tan decentes, y que los africanos van a dar la ley. El Carabali ${ }^{15}$.

\section{LA MUJER AMERICANA ANTE EL CONFLICTO INDEPENDENTISTA}

4.1. No resulta extraño, pues, que en El Procurador se publicara el manifiesto patriótico de las damas montevideanas, vibrante llamada a la defensa de su ciudad, por entonces bastión realista asediado por los porteños y por los orientales de Artigas, como Cádiz estaba sitiado por el francés. El grupo de mujeres orientales reclama el ejemplo de "aquellas nobles hispanas" significadas en la guerra peninsular contra los ejércitos napoleónicos, "las valientes geronesas, / también las aragonesas / y las gallegas leales", en alusión a los sitios de Gerona y Zaragoza, que tanta repercusión alcanzaron en la América española, los sufridos por la capital de Aragón sobre todo ${ }^{16}$. La animadversión hacia Napoleón fue corriente entre los criollos, no solo los partidarios de la causa realista, sino también muchos de los que seguían el partido independentista. De los primeros encuentro una muestra en la burlesca Proclama de un chusco de Arequipa de hacia 1810, cargada de vituperios sobre "ese bruto de Bonaparte", "ese chasca atrevido", "ese vil motilón", "este monstruo de todos los diablos" (2012b: 70-72); referente a

15 Número 32, 1 de noviembre de 1812, pp. 260-261.

16 Es claro que el verso "han dado fuego al cañón" alude a la heroica acción de Agustina de Aragón. 
los insurgentes hallo otro ejemplo en las décimas bogotanas de 1814 donde se llama Sapoleón al emperador francés (2011: 330 ${ }^{17}$.

4.2. Refiere Cantos Casenave que no son muchas las muestras de literatura política femenina, y que al parecer abundó más en España que en América, adonde pertenece el manifiesto de las Barinesas incluido en la Gaceta de Caracas el 5 de noviembre de 1811, cuyas firmantes -varias, pues, como en el de Montevideo- se declaran dispuestas a presentarse en el campo de batalla (2011: 129). Mujeres patriotas de la breve Primera República eran estas, mientras el fervor español alienta en la Proclama de doña María Francisca de la Nava, mexicana llena de entusiasmo y amor acia su Soberano el Señor Don Fernando VII (¿1808?), escrito por la autora para animar a sus compatricias a la liberación del monarca preso en el castillo de Valençay; bien es verdad que este texto es inmediatamente anterior a la eclosión independentista (Cantos Casenave 2008: 229-230) ${ }^{18}$.

A favor de la continuidad de la situación virreinal estaban las damas de Montevideo en su literario manifiesto, "defenderemos nosotras / los derechos de Fernando" (IX, 9-10), en la misma línea ideológica que la novohispana Nava y semejantes a ella en cuanto a su elevada posición social, muy distinta sin duda de la de aquel nutrido grupo de mujeres que formaban parte de las tropas de Sámano en Popayán, según relata José Gregorio Gutiérrez Moreno en carta datada el 28 de julio de 1813 en Santafé de Bogotá: "Dicen que trae cerca de 2000 hombres, y solo 800 fusileros, entrando en este número 150 mujeres vestidas de hombre para cuidar a la tropa" (Vanegas Useche 2011:

17 Son muchos los textos de americanos independentistas que refieren menosprecio o recelo hacia Napoleón, bien porque se le veía como enemigo de la religión, bien porque se sospechaba que pretendía apropiarse de la América española, como había hecho con la mayor parte del territorio peninsular. Wold recoge testimonios del tratamiento de la cuestión napoleónica en el Diario de México (1970: 138-150).

$18 \mathrm{Ni}$ en este caso ni en el de Una fiel habanera (v. n. 21), tampoco en el de las cuatro damas de La Habana que en 1810 proponían la formación de una compañía de mujeres para que se unieran al ejército peninsular (Cantos Casenave 2008: 183), la efectividad militar era posible, por lo cual los manifiestos de buenas intenciones en la práctica se reducían a la solicitud de ayudas económicas para los combatientes de España. Como en otra parte he señalado, semejantes propuestas de suscripciones en dinero y joyas menudearon en América, y la colecta es realmente la primera finalidad en la Proclama del chusco arequipeño: "hagamos plata vendiendo nuestros aperos..., mandemos nuestras limosnas a los que están en España peleando..." (2012b: 72, 76). En cuanto a la novohispana María Francisca de la Nava, su obra de título Sueño alegórico dedicado a la religión, objeto amable de la antigua y Nueva España (1809), fue anunciada en el Diario de México, el 16 de febrero de este año (Wold 1970: 260). 
417). Pero el ardor patriótico y guerrero del elemento femenino seguramente estuvo más vivo y extendido del lado de la insurgencia ${ }^{19}$.

4.3. En defensa de Fernando VII era la femenina arenga de las mujeres cisplatinas, que viene precedida en el mismo número de El Procurador por el artículo de un convencido fernandista y acérrimo contrario de las reformas liberales, que lo concluye con un "¡Viva Fernando VII, muera Napoléon!”. Era, pues, muy oportuna la inclusión del Manifiesto montevideano en este papel gaditano, como lo era por su espíritu combativo y su reprensión de la cobardía varonil ("y mientras los maricones / resposan en lecho blando...": IX, 5-6): apenas seis meses antes en dicho periódico el articulista anterior al que se firma como El Carabalí anima a los escritores reformistas a que "salgan de esa vida muelle y afeminada", y los reprende:

Nadie más que los escritores grita que todos somos iguales; den pues un testimonio de ello esos escritores charlatanes, valientes fuera de los riesgos y guapos sin enemigos que combatir, poniéndose en las mismas filas del honrado labrador, que vale tanto como ellos (v. n. 15).

Gran cercanía cronológica hay asimismo entre la presencia en la prensa gaditana de este Memorial (21 de abril de 1813) y los sucesos a los que en él se aluden, cuando en el cerco de Montevideo participaban los porteños de Rondeau ("verá cómo paga caro / Rondeau su orgullo y arrojo": XI, 7-8), y gentes del interior de la Banda Oriental bajo el mando de Artigas, quien el 9 de abril de 1813 convocó en Tres Cruces el Congreso Oriental, y en el texto comentando se lee:

Que si es preciso saldremos

al Christo o las Tres Cruces

a desplumar avestruces

de los que al frente tenemos (I, 7-10 $)^{20}$

19 Recuérdense a la heroína venezolana conocida como La Amazona Trujillana (v. n. 21), a las mujeres que intervinieron en la batalla de Boyacá o a las que en 1811 formaron en Quito un batallón para atacar una plaza fuerte realista en Cuenca (Cantos Casenave 2008: 186-187).

20 Como avestruces (en el texto Aves Truces), las autoras evitan el indigenismo guaraní $\tilde{n} a n d u$, son despectivamente llamadas las huestes que cercaban Montevideo, en buen número habitantes de las pampas argentinas y orientales, "esa vil e infame raza" (VIII, 8). 
Teniendo en cuenta todo esto, es muy posible que el Memorial se escribiera en fecha no muy alejada de la referida, por consiguiente con no demasiada antelación a su publicación en El Procurador el 21 de dicho mes, y parece probable también que en aquel ínterin se imprimiera en algún papel uruguayo, una de cuyas copias acabaría en manos del editor gaditano. El momento político en que las protagonistas del poema vivían se manifiesta en la voz insurgente (II, 9), y el ambiente bélico en los términos antemurales (IV, 10), batir (II, 9), cartucheras (IX, 2), confites silbadores 'proyectiles de armas de fuego' (III, 5), desalojar el cordón (VIII, 7), enristrar la lanza (V, 9), espadas tizonas $(\mathrm{V}, 10)$.

\section{ARGUMENTACIÓN FEMENINA Y EXPRESIÓN FORENSE}

5.1. La forma confites silbadores es de sentido figurado y uso coloquial; de hecho, la segunda acepción de bala en el diccionario académico es 'confite redondo, liso, todo de azúcar', ya desde el Autoridades (aquí 'liso o con piquillos'), y confite es 'bala o piedra' en hablas andaluzas (Alcalá Venceslada 1980: 164), coloquialismo que asimismo reside en la secuencia desplumar avestruces, para referirse al elemento campesino o gauchesco de las fuerzas sitiadoras (I, 8). Varios son los registros de expresiones metafóricas y burlescas, así "entre sayas y calzones / la diferiencia no es mucha" (VI, 5-6), "pues a infinitos les faltan / las barbas y los bigotes" (VII, 9-10), "mientras otros se entretienen / pintando al Padre Simón" (X, 9-10). La tradicional contraposición de las sayas a los calzones para distinguir la valentía, presupuesta para el hombre, la rebaten las aguerridas montevideanas en varios versos de estas décimas, de nuevo en "que baxo nuestras polleras / se verán muchos calzones / y mientras los maricones / reposan en lecho blando..." (IX, 3-6). Y está el argumento erudito, propio de un entorno social cultivado, que las féminas orientales esgrimen en apoyo de su arrojada demanda: "nosotras tenemos arte / para vencer a Cupido, / y qué ¿no será rendido / Júpiter y el mismo Marte?" (X, 1, 4), identificando su gallardía con las "valientes Amazonas" (V, 7), genuino mito del imaginario colectivo americano ${ }^{21}$. El tono de esta pieza literaria es sin duda culto, lo que no quita

21 Mito que tuvo frecuente presencia en la literatura de la América virreinal, también en la época que nos ocupa, y famoso es el caso de la heroína independentista Bárbara de la Torre, 
que se perciba una cierta sintonía con la poesía popular en estos versos, de afinidad gauchesca:

La mujer estando en lucha

con el demonio pelea,

y el más guapo tituvea

si se presenta en la lucha (VI, 6-10).

5.2. El texto montevideano sigue la estructura formal del documento administrativo y forense que era el memorial, en definición académica 'papel o escrito en que se pide una merced o gracia, alegando los méritos o motivos en que se funda la solicitud', con sinónimo instancia que también figura en la composición poética ("vista la instancia presente...": XI, 2). Va precedido del obligado preámbulo (el sexteto-lira) y seguido del decreto 'resolución de carácter político o gubernativo' (la octava), con el proveído del derecho procesal en lenguaje de la escribanía pública y notarial de la redondilla final: "lo mandó, de que doy fe, / por ante mí el Escribano". El lenguaje forense es palmario en la octava del decreto, "por presentada se tenga y córrase traslado a los hombres..., y, ya informado por su respuesta, oiré a las heroynas si deben o no tratarlos de gallinas", lo que al menos hace creíble la colaboración del hombre ducho en asuntos de gobierno y de estrados judiciales. Asimismo se afianza la idea de que el Memorial se escribió con fines propagandísticos y para provocar los ánimos de los que no mostraban su compromiso con la defensa de Montevideo; y se refuerza la oportunidad de su pronta publicación en un periódico de Cádiz que igualmente reprochaba el desinterés guerrero de algunos habitantes de la ciudad asediada (cfr. 4.3.).

Los versos que comento a las claras delatan anhelos propios de mujeres adelantadas para la época, en cuanto a su incursión en una literatura políticamente comprometida y de difusión pública, también en cuanto al intento de romper barreras de exclusividad masculina, contrarias a la

conocida como La Amazona Trujillana. La proclama de Una fiel habanera a sus paisanas, firmada el 9 de agosto de 1808 en La Habana, lo registra en manifestación del odio de su autora a los invasores franceses de la Península: "vosotros mismos pereceríais a manos de las Amazonas habaneras" (Cantos Casenave 2008: 244). Pero, como en tantos otros casos, siendo la acción militar imposible para estas animosas cubanas, la escritora ha de reducir su manifiesto al lado práctico de la ayuda para los resistentes peninsulares mediante la oración y la contribución económica: "El dinero es el nervio de la guerra: pues deshagámonos de todas nuestras joyas, hasta el servicio de oro y plata de nuestras casas..." 
participación femenina en la acción militar, pues aunque "habrá algunas opiniones / contrarias a nuestro intento" (VI, 1-2), piden la excepción para competir con los hombres en el campo de batalla: “... bien podemos, / por una ley exclusiva / entrar en la alternativa / con ellos y así lo haremos" (VIII, 1-4).

\section{EL ASPECTO LINGÜÍSTICO}

6.1. La ortografía del texto en cuanto a puntuación y tildado, tanto el de carácter fonético como el correspondiente a la preposición $a$ y a las conjunciones $e$ y $o$, con predominio del rasgo (') sobre el trazo ('), se corresponde con la más usual en otras páginas de El Procurador y otros periódicos gaditanos, siguiendo normas que iba dictando la Real Academia Española, pero también con bastantes desvíos y rémoras de la tradición escrituraria. Se mantiene regularmente la aplicación del circunflejo a la vocal siguiente a la $x$ de pronunciación /ks/, preconizada por la Ortografía académica de 1741 (exâltan, exâminado, exîge, sexô), y los dos puntos (:) se emplean constantemente al final del cuarto verso de cada décima, menos en el de la IV, que lleva coma, y el de la X, acabado en signo de interrogación, en línea con acendrada tradición en soportes escritos de esta estrofa. En casi todo la coincidencia ortográfica de este texto de publicación peninsular con tantos otros impresos americanos es grande, y aunque sería inútil imaginar con qué ortografía vendría el papel del Río de la Plata, al menos es presumible que fuera en letra de molde, quizá por el referido uso sistemático de los dos puntos y también por la difusión propagandística que el Memorial tendría en Montevideo.

6.2. En cuanto a la fonética, un registro meramente ocasional de diferiencia (VI, 6) no es en la lengua escrita de la época señal evidente de incultura, pues esta alteración vocálica aparece aisladamente en no pocos textos de americanos cultos, así en uno del mexicano fray Manuel de Mercadillo de $1822^{22}$. Es más, en los versos del Memorial no solo no se aprecia un solo

22 Carta de Fr. Manuel de Mercadillo a don José Joaquín Fernández Lisardi, conocido por El Pensador de Méjico, 17 de abril de 1822: BNE, Mss. 21345-1, f. 7v. 
caso de antihiatismo, fenómeno de tanto arraigo en el español americano de entonces, sino tampoco la sinéresis métrica: creemos (II, 2; VIII, 5), deseamos $(\mathrm{V}, 8)$, tituvea (VI, 9), salvo la solución antihiática de oiré (oi-ré) de la octava, condicionada quizá por el comentado conflicto entre el estilo forense y la forma literaria (cfr. 2.1.).

6.3. Los grupos consonánticos cultos (latinizantes) se preservan sin excepción en sus numerosos registros: acción, exaltan, examinada, exclusiva, exige, instancia, lecciones, obtienen, magnánima, perfecciones, pretexto, sexo. Tampoco se observa el desliz seseoso, normal en los textos americanos de la época, aunque con frecuencia variable según el rango cultural de cada autor, y generalmente más abundante en manuscritos que en impresos, faltando asimismo la manifestación cacográfica del yeísmo, que las gentes cultivadas solían rehuir. Es claro, pues, que si se tuviera presente una muestra uruguaya del mismo corpus literario sería pertinente el análisis comparativo, porque en las referidas cuestiones no cabe descartar que en su posible edición montevideana no se siguieran las mismas normas establecidas para la publicación de El Procurador.

6.4. Desde el punto de vista gramatical, aparte del formulario por ante mi ya señalado (cfr. 5.2.), dos notas hay referentes al especial apego a la tradición del español americano; el registro como masculino de dotes 'prendas, cualidades' en primer lugar, "obtienen aquellos dotes / que al buen militar exaltan" (VII, 7-8), cuando según Corominas y Pascual ya en el siglo XVIII su género femenino era el más frecuente (1980-1991: II, 520), y lo propio cabe decir de habemos auxiliar ("las que habemos concebido": IV, 2), si bien aquí se puede pensar en un uso literario de la variación sociolingüística, pues con hemos y sinalefa el verso sería heptasílabo.

6.5. El galicismo bello sexo se había difundido en el español culto; caloroso (III, 7), pero parece que era más corriente en el español de América que en el de España, y mayor era el grado de diferenciación diatópica respecto a pollera (IX, 3), todavía con notable pervivencia americana frente a su residual testimonio malagueño (Alvar Ezquerra 2000: 641); y la cuestión de la diversidad gradual asimismo se sustancia en el uso de guapo "valiente, valentón' ("y el más guapo tituvea": VI, 9), entonces genuino vocablo del 
lenguaje gauchesco y americanismo general por ser ya de arraigo más extendido que en el español europeo ${ }^{23}$.

\section{CODA}

La participación de la mujer en la creatividad textual americana de fondo patriótico, político y de compromiso social encontró terreno abonado en las convulsiones sufridas por América en la época de las independencias, y en las décadas de asentamiento de las nuevas Repúblicas. En el género epistolar hay numerosísimas muestras del afán femenino por la escritura, pero asimismo se descubre el interés de las americanas por la expresión literaria de sus posturas ante los acontecimientos que vivían. El Memorial montevideano es un ejemplo de lo que en este campo de investigación puede hacerse y de lo mucho que queda por hacer.

Si al aspecto lingüístico del Memorial nos atenemos, sus no muchas notas diatópicamente diferenciadoras remiten a un modelo de uso indiscutiblemente culto, y es claro que con muchos más datos se tiene que ir determinando el español de la elite criolla de toda América y por regiones. Es cuestión también de avanzar en el conocimiento de la escala normativa en el espectro social hispanoamericano, y para el mismo Uruguay de aquellos años tendremos los escritos sumamente populares del negro Molina (2010), con numerosas cacografías seseosas y varias de yeísmo, con vulgarismos fonéticos como el del antihiato (almuada, Juaquín), consonánticos - recao, tohavía, maldá, continuas alteraciones en grupos consonánticos, etc.-, y en morfología (dentrar, onde, quedré, sujetastes). Un nivel medio-alto lo ofrece la Gaceta de Canelones editada en 1826-1827 (González, Lucuix y Scarone 1943), con seseo grafemático pero sin confusiones yeístas, con algún desliz vulgar (ahijoneado 'aguijoneado'), y testimonios del apego a la tradición, verbigracia: "con quién las habemos", "no haber pronunciádose", cualesquiera establecimiento, cualesquiera precio. $\mathrm{Y}$ en este periódico oriental he hallado la recreación del lenguaje gauchesco con sus característicos rasgos idiomáticos (2013: 8-9), debida a autor anónimo sumamente culto, que empareja dicho texto de tipo marcadamente popular con una composición poética de gran corrección normativa. 


\section{REFERENCIAS BIBLIOGRÁFICAS}

Alcalá Venceslada, Antonio. 1980. Vocabulario andaluz. Madrid: Editorial Gredos.

Alvar Ezquerra, Manuel. 2000. Tesoro léxico de las hablas andaluzas. Madrid: Arco Libros.

Cantos Casenave, Marieta. 2008. "Las mujeres en la prensa entre la Ilustración y el Romanticismo". En Marieta Cantos Casenave et al. (eds.). La guerra de la pluma. Estudios sobre la prensa en Cádiz en el tiempo de las Cortes (1810-1814), III. Sociedad, consumo y vida cotidiana. Cádiz: Servicio de Publicaciones de la Universidad de Cádiz, 162-336.

2011. "Las mujeres en la era de 1812. De tapadas a excluídas". En Alberto Ramos Santana (ed.). La constitución de Cádiz y su huella en América. Cádiz: Servicio de Publicaciones de la Universidad de Cádiz, 125-139.

Castro y Rossi, Adolfo de. 1857/2007. Nombres antiguos de las calles y plazas de Cádiz. Edición facsimilar, Mairena del Aljarafe (Sevilla): Extramuros Edición.

Corominas, Joan y José A. Pascual. 1980-1991. Diccionario crítico etimológico de la lengua castellana. Madrid: Editorial Gredos.

Cruz GonzÁlez, CARlos. 2006. "La imprenta Tormentaria de Cádiz: estudio y catalogación”. En Marieta Cantos Casenave et al. (eds.). La guerra de la pluma. Estudios sobre la prensa de Cádiz en el tiempo de las Cortes (1810-1814, I. Imprentas, literatura y periodismo. Cádiz: Servicio de Publicaciones de la Universidad de Cádiz, 113-165.

Frago, Juan Antonio. 2010. El español de América en la Independencia. Santiago de Chile: Taurus.

2011. "Cuestiones de norma lingüística en décimas de la insurgencia colombiana". Onomázein 24/2: 327-348.

2012a. "Lecciones lingüísticas en versos mexicanos de la Independencia". Boletín de la Real Academia Española 92/305: 59-84.

2012b. "Cruces normativos y dialectales en la Proclama del chusco de Arequipa (c. 1810)". BFUCh 47/1: 69-88.

2013. "El lenguaje gauchesco: caracteres y contexto normativo". Ínsula. Revista de Letras y Ciencias Humanas 793-794: 7-10.

González, A. D., S. Lucuix y A. Scarone (eds.). 1943. Gaceta de la Provincia Oriental. Canelones 1826-1827. Edición facsimilar, Montevideo: Instituto Histórico y Geográfico del Uruguay.

Molina, Jacinto VentuRa De. 2010. Los caminos de la escritura negra en el Río de la Plata, William G. ACreE Jr. y Álex BorUCKI (eds.). Madrid: Iberoamericana.

Quilis, Antonio. 1975. Métrica española. Madrid: Ediciones Alcalá.

Quintero GonZÁlez, José. 2011. "E1 legado americano de las Cortes de la Isla de León (24 de septiembre de 1810-20 de febrero de 1811)". En Alberto Ramos Santana (ed.). La constitución de Cádiz y su huella en América. Cádiz: Servicio de Publicaciones de la Universidad de Cádiz, 289-298.

Rodríguez Gutiérrez, María. 2006. "Las modalidades literarias en la prensa de las Cortes de Cádiz: el caso de El Procurador General de la Nación y del Rey (1812-1813)”. En Marieta Cantos Casenave et al. (eds.). La guerra de la pluma. Estudios sobre la prensa de Cádiz en el tiempo de las Cortes (1810-1814), I. Imprentas, literatura y periodismo. Cádiz: Servicio de Publicaciones de la Universidad de Cádiz, 305-389.

SÁnchez Hita, BeAtriz. 2006. "La imprenta en Cádiz durante la guerra de la independencia y su relación con la prensa periódica". En Marieta Cantos Casenave et al. (eds.). La guerra de la pluma. Estudios sobre la prensa de Cádiz en el tiempo de las Cortes (1810-1814), I. Imprentas, literatura y periodismo, 31-111. 
VANEGAS Useche, ISIDRo (comp.). 2011. Dos vidas, una revolución. Epistolario de José Gregorio y Agustín Gutiérrez Moreno (1808-1816). Bogotá: Editorial Universidad del Rosario.

Wold, Ruth. 1970. El Diario de México, primer cotidiano de Nueva España. Madrid: Editorial Gredos. 